\title{
MASCARADAS DE RUA - ENTRE O RITUAL, A FESTA E A PATRIMONIALIZAÇÃO
}

Silvia Sueli Santos da SILVA

\begin{abstract}
RESUMO
O objetivo deste artigo é proporcionar uma reflexão sobre os novos significados e apropriações dos antigos rituais com máscaras, presentes em todos os continentes, a partir das festas contemporâneas. Para tal, elegeu-se as aproximações entre a brincadeira do Boi de Máscaras - São Caetano de Odivelas (PA) e as Mascaradas de Inverno da região de Trás-os-Montes (PT). O texto apresenta a rua como o espaço lúdico, propício às brincadeiras e à digressão coletiva, tal qual se expressa nos rituais com máscaras, festas ligadas ao tempo cíclico que têm a rua como locus privilegiado onde as culturas renovam seus fazeres por meio do imaginário e da memória de suas tradições. O fenômeno das mascaradas contemporâneas atualiza as funções ancestrais da máscara como mediadora entre o mundo natural e sobrenatural, mas agrega aos ritos festivos o comportamento lúdico, a brincadeira e a espetacularidade. Discute-se a questão atual da patrimonialização das mascaradas de rua como bens imateriais e as implicações nas comunidades, nas quais as festas representam a ligação entre tradições ancestrais e as novas gerações, que delas participam, contribuindo de forma significante para sua transformação e reconhecendo-se nelas, como sujeitos híbridos e integrados a sua cultura.
\end{abstract}

Palavras-chave: Brincadeira de rua; Festa; Boi de máscaras; Mascaradas de Inverno.

\section{STREET MASQUERADES - BETWEEN RITUAL, FESTIVITIES AND PATRIMONIALISATION}

\begin{abstract}
This paper aims to proportionate a reflection over the new meanings and appropriations of the ancient rituals with masks, present in all continents, based on contemporaneous festivities. For such, it elects the approximations between the Ox of Masks playing - São Caetano de Odivelas (PA) and the Winter masquerades of the Trás-os-Montes region (PT). The text presents the street as a ludic space, propitious to playing and collective digression, such as it's expressed in the rituals with masks, festivities bonded to the cyclic time that has the street as priviledged locus in which Cultures renew their making by means of the imaginary and memory of their traditions. The phenomenon of the contemporaneous masquerades updates the ancient functions of the mask as mediator between natural and supernatural, but aggregates to the festive rites the ludic behavior, the playing and the spectacularity. It debates the current question of the patrimonialisation of street masquerades as immaterial goods and its implications in the communities, in which the festivities represent the connection between ancient traditions and the new generations, which participate in them, contributing in a significant way for their transformation and recognizing themselves in them, as subjects that are hybrid and integrated to their Culture.
\end{abstract}

Keywords: Street Playing; Festivity; Ox of Masks; Winter Masquerades.

\section{ENMASCARADAS DE LA CALLE - ENTRE EL RITUAL, LA FIESTA Y LA PATRIMONIALIZACIÓN}

\section{RESUMEN}

El objetivo de este artículo es proporcionar una reflexión sobre los nuevos significados y apropiaciones de los antiguos rituales con máscaras, presentes en todos los continentes, a partir de las fiestas contemporáneas. Para esto, se eligieron las aproximaciones entre la broma del Boi de Máscaras - São Caetano de Odivelas (PA) y las Enmascaradas de Invierno de la región de Trás-os-Montes (PT). El texto presenta la calle como el espacio lúdico, propicio a las bromas y a las giras colectivas, tal cual se expresa en los rituales con máscaras, fiestas ligadas al tiempo cíclico que tienen la calle como locus privilegiado
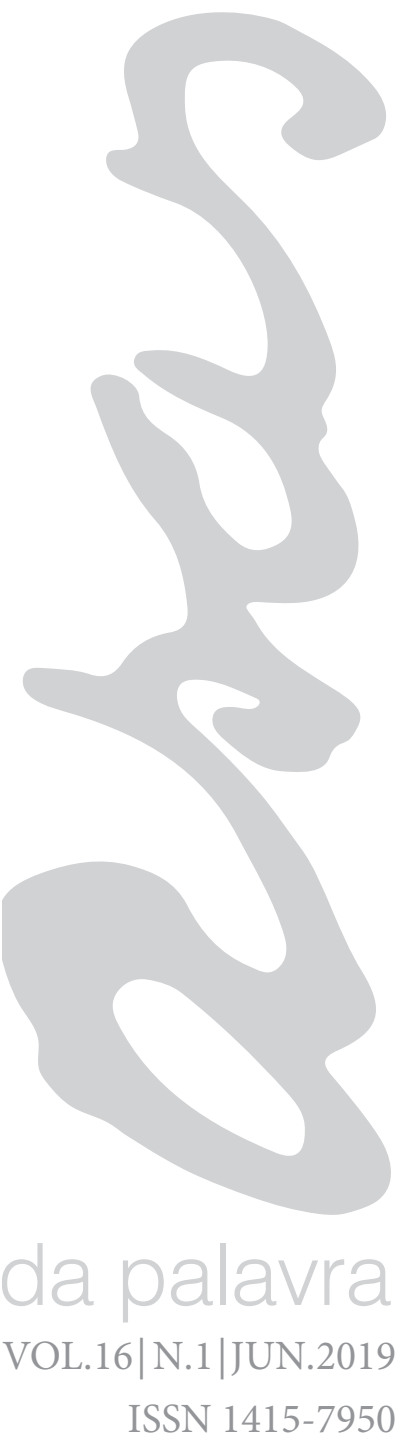
donde las culturas renuevan sus haciendas por medio del imaginario y de la memoria de sus tradiciones. El fenómeno de las enmascaradas contemporáneas actualiza las funciones ancestrales de la máscara como mediadora entre el mundo natural y sobrenatural, pero agrega a los ritos festivos el comportamiento lúdico, el broma y la espectacularidad. Se discute la cuestión actual de la patrimonialización de las mascaradas callejeras como bienes inmateriales y las implicaciones en las comunidades, en las cuales las fiestas representan el vínculo entre tradiciones ancestrales y las nuevas generaciones, que de ellas participan, contribuyendo de forma significante para su transformación y reconociendo, si en ellas, como sujetos híbridos e integrados a su cultura.

Palabras clave: Bromas de calle; Fiesta; Boi de Máscaras; Enmascaradas de Invierno.

\section{INTRODUÇ̃̃O}

Pieter Brueghel, o Velho (1525/30-1569) em sua obra Jogos Infantis (1560), retrata cerca de oitenta jogos, tendo a rua como cenário, espaço lúdico para as brincadeiras coletivas. O pintor do século XVI cuidou com perícia de demonstrar a ação representada em cada quadro, de modo que grande parte desses jogos pode ser identificada pela expressão gestual dos corpos que brincam no espaço. Nota-se na obra a indefinição das expressões faciais dos personagens da cena, como se, postos ali, suprimissem toda emoção individual e imergissem num corpo coletivo, formado por toda a comunidade brincante. A brincadeira de rua, como momento de encontro para a diversão compartilhada, permite a participação simultânea de todos os grupos etários indistintamente, portanto, na obra de Brueghel a brincadeira de rua toma aparência de tradição, condicionando-se como atividade ligada à infância permitida a todas as idades, sem hierarquias e sem tempo determinado, exceto por se caracterizar pela suspensão da labuta cotidiana.

Na brincadeira de rua, encontro "organizado" no espaço público, três elementos distinguem a digressão coletiva: o riso, a liberdade de ir e vir e a interrupção momentânea das atividades cotidianas, como prerrogativas comuns que identificam as práticas lúdicas, conotando para essa atividade coletiva a expressão de acontecimento festivo. Cenas como a formação de cordões humanos que transitam pelo meio da multidão, as cavalgadas nos cavalinhos de pau, e as meninas girando as saias, são exemplos de práticas retratadas em Jogos Infantis nas quais é possível reconhecer inúmeras influências nas festas contemporâneas luso-brasileiras.

A teatralidade como "o jogo cotidiano das interações face a face, onde somos simultaneamente atores e espectadores" (BIÂO, 2009, p.163) é um comportamento presente na brincadeira de rua, nela, cada participante interpreta um papel ou muitos papéis diferentes de sua rotina diária. No exemplo da obra de Brueghel, os meninos sentados na cerca gesticulam como cavaleiros montados em seus corcéis, enquanto o grupo brincando de pira no canto superior direito do painel encena uma "verdadeira batalha épica". Desse modo, a teatralidade do ato de brincar está por todos os cantos sem que, em nenhum momento, qualquer um dos personagens envolvidos se dê conta do olhar do outro para si, tal é sua concentração na execução de sua função no jogo.

O corpo que brinca é um corpo lúdico, e, como tal, comunica por seus movimentos espontâneos um estado alterado de consciência, mesmo que, posteriormente, quando terminada a brincadeira, possa narrar suas ações com exatidão, pois, o "saber fazer" que se repete "trata-se de um saber não sabido. Há, nas práticas, um estatuto análogo àquele que se atribui às fábulas ou aos mitos, como os dizeres de conhecimentos que não se conhecem a si mesmos" (CERTEAU, 1996, p. 143, grifo do autor). A brincadeira de rua, saber fazer compartilhado por todas as culturas, reconhecida e extensiva a 
REVISTA DO PROGRAMA DE PÓS-GRADUAÇÃO EM COMUNICAC̨ÃO, LINGUAGENS E CULTURA DA UNIVERSIDADE DA AMAZÔNIA

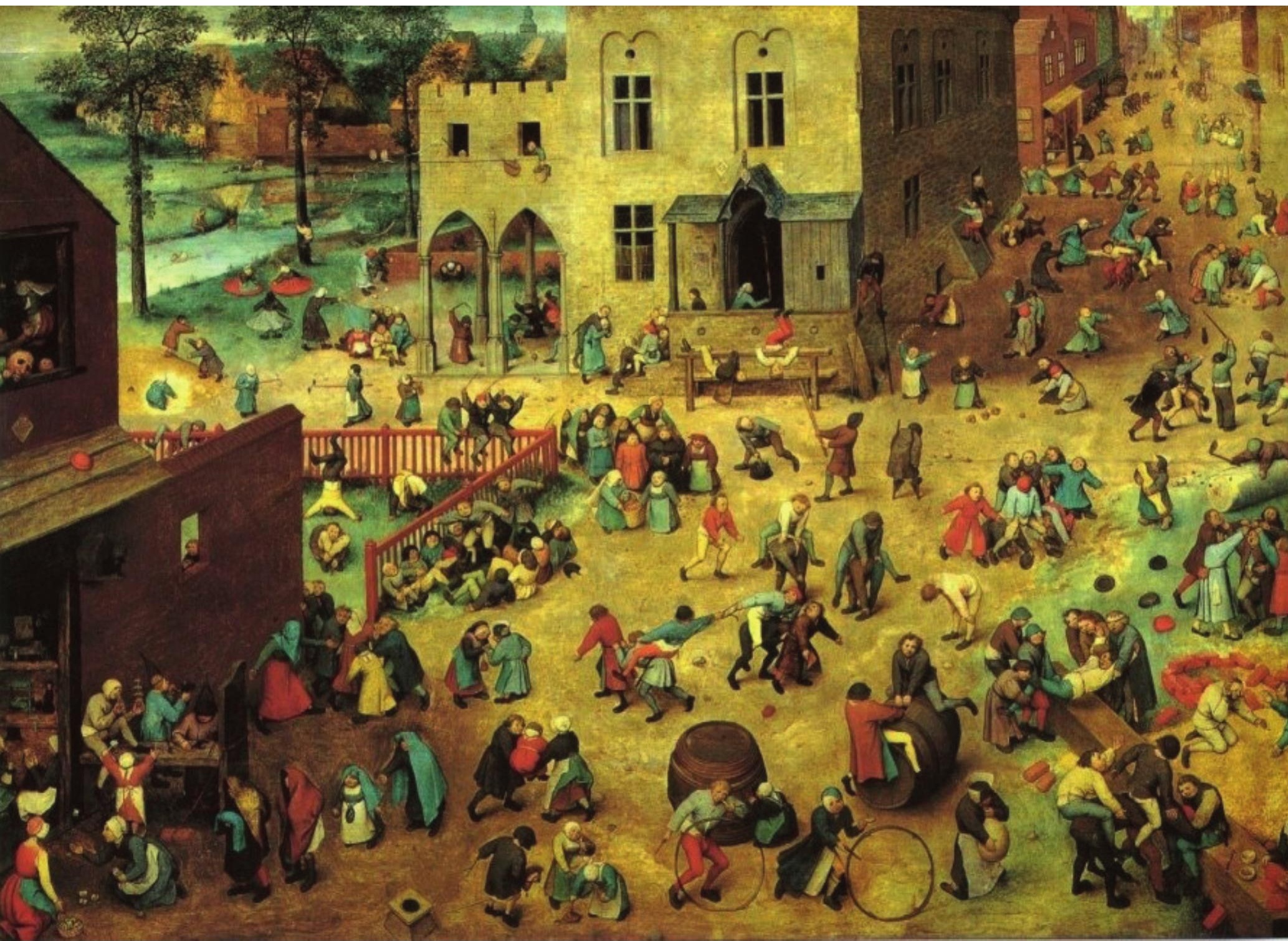

Figura 1: detalhe da obra Jogos Infantis - Pieter Brueghel, o Velho (1560): painel a óleo,118 $\mathrm{cm}$ x $161 \mathrm{~cm}$, Museu da História da Arte, Viena, Áustria. Fonte : https://virusdaarte.net/pieter-bruegel-o-velho-jogos-infantis/ 
uma comunidade periodicamente, traduz-se em suas festas tradicionais.

A festa é a ocasião em que a brincadeira, extrapolando sua condição de espontaneidade sem tempo fixo, oficializa-se como rito. Oficializar não é necessariamente a aceitação do poder político constituído, mas o reconhecimento, por parte de uma comunidade, da continuidade do rito festivo, pois é por ela que a festa será reproduzida nos anos seguintes de sua criação. O tempo da festa passa, pois, a ser um tempo suspenso, aquele que é, conforme assinala Eliade, "[...] o tempo mítico, que como um tempo sagrado é indefinidamente recuperável, indefinidamente repetível" (1992, p. 38). A atualização da festa encontra-se ligada ao tempo cíclico, tal qual o calendário oficial, sendo também o seu locus, igualmente envolvido neste momento de suspensão do cotidiano, à medida que o espaço transformado pela festa, torna-se "um lugar praticado" (CERTEAU, 1996). A rua, transformada pela presença da festa, deixa de ser a via de pedestres e veículos e passa a ser o cenário ocupado por atores anônimos, palco aberto ao imaginário, no qual não há começo nem fim para a entrada e saída, há apenas o trajeto da festa, dialogando com os corpos que participam desta "dramaturgia caminhante" (SANTA BRÍGIDA, 2006).

\section{FESTA, BRINCADEIRA E ESPETACULARIDADE}

É certo que toda festa contém em si algo de espetacular, mas esse estado não implica necessariamente na existência fixa do espectador, pois grande parte dos que dela participam está em pleno comportamento lúdico, envolvidos em seu estado de liminaridade. Duvignaud explica que os suportes da festa são a empatia ou a proximidade, constituindo-se em experiência que intensifica as relações emocionais e os contatos afetivos, permitindo um nível de comunicação em que se "efetua, repentinamente, uma abertura recíproca entre as consciências na medida em que a festa não mais necessita de símbolos e inventa suas figurações que desaparecem, muitas vezes, em seguida perecíveis" (1983, p. 68). Portanto, cabe aqui uma distinção entre festa e espetáculo: "O espetáculo é ao mesmo tempo parte da sociedade, a própria sociedade e seu instrumento de unificação [grifos do autor]. Enquanto parte da sociedade, o espetáculo concentra todo o olhar e toda a consciência" (DEBORD, 2003, p. 9). O segundo termo é aplicado usualmente no sentido da atividade organizada em função da alteridade. Nele, o espaço é demarcado de forma fixa ou improvisada, distinguindo-se o público que assiste (espectador) daqueles que atuam.

Nas festas de rua, o espetacular está no olhar daqueles que se deslocam para ver a festa de perto. Para estes, ela se apresenta como momento de contemplação dos sentidos, com todos os seus elementos espetaculares: a música, a dança, a encenação e a visualidade, mas também os gestos, as expressões corporais, os olhares contritos, por vezes devotos até as lágrimas, e o riso festivo, espontâneo e até contagiante. Por se tratar da primazia do lúdico acima do desejo de convocar a alteridade, a festa está mais aberta à espetacularidade do que ao espetáculo. Quando se torna espetáculo, a festa tende a deixar seu locus privilegiado e a confinar-se no recinto fechado, no qual entre outras perdas, suprime-se a democracia do ir e vir condicionada pelo espaço da rua. Na espetacularidade revela-se a condição liminal, na qual é o sujeito que se expressa para o olhar do outro, sem, contudo, assinalar a separação entre atores e espectadores, que fica evidente no espetáculo. A espetacularidade é, portanto, definida como "a categoria dos jogos sociais onde o aspecto ritual ultrapassa a rotina: são os rituais religiosos, as competições esportivas, os desfiles e comícios, as grandes festas" (BIÃO, 2009, p. 163-164). 
e identitário, denominadas mascaradas, fazem parte do calendário festivo das ruas brasileiras e portuguesas desde tempos imemoráveis. O estudo das mascaradas como fenômeno contemporâneo implica no reconhecimento de suas matrizes culturais e estéticas, elo que perpassa o universo significante das práticas espetaculares, evidenciado nos ritos festivos tanto em terras brasileiras, quanto em solo português. Elegeu-se para esta pesquisa a mascarada de rua denominada Boi de máscaras, brincadeira de boi da cidade brasileira de São Caetano de Odivelas, município do estado do Pará, e, em paralelo, as Festas de Inverno, do Nordeste transmontano, com seus grupos de Caretos e suas manifestações sazonais, mascaradas portuguesas da região de Trás-os-Montes e Alto Douro.

Os estudos das mascaradas a partir da investigação do fenômeno contemporâneo chamam atenção para novos olhares estéticos e reflexivos sobre os saberes culturais que perpassam essas festas, que para seus atores são cotidianamente nomeadas como brincadeiras de rua: a "brincadeira do boi"/ a "brincadeira dos Caretos". Nesta perspectiva, o espaço da rua aparece como lugar do encontro comunitário, no qual as diferentes gerações experimentam sua nova face, literalmente transfigurada em persona, a imagem composta pela máscara e o corpo de seu portador, a ser apresentada à alteridade, constituindose por vezes a personificação da subversão, do enfrentamento, da jocosidade, dos delírios humanos. Torna-se a máscara o instrumento de empoderamento que permite ao sujeito olhar de dentro de sua cultura e integrar-se a suas expressões simbólicas, como sendo ele próprio a expressão viva desta cultura.

\section{A MASCARADA ENTRE O RITUAL E A BRINCADEIRA}

Do ritual agrário de renovação do mundo sagrado à digressão contagiante do mundo invertido das festas carnavalescas, o mascarado é presença impar nas festas de rua das culturas luso-brasileiras, pode-se dizer, das culturas íbero-americanas. Em todas, a marca herdada de festas ancestrais se atualiza nos festejos contemporâneos, pois, como explica Duvignaud (1983), a festa representa um momento de ruptura no fazer cotidiano de uma sociedade, momento propício a toda digressão e ao encontro comunitário. Nela, percebe-se o delírio proporcionado pela entrega total dos corpos ao estado lúdico: "a festa se apodera de qualquer espaço onde possa destruir e instalar-se. A rua, os pátios, as praças, tudo serve para o encontro de pessoas fora das suas condições e do papel que desempenham em uma coletividade organizada" (1983, p. 68).

Como interdito para o desconhecido, a máscara encontra-se no meio de dois mundos, o visível e o invisível. Minois (2003) explica que a função social da máscara como mediadora entre o mundo terreno e o mundo espiritual aparece desde a festa arcaica. Nela, manifesta-se o sentido de simulacro do mundo humano, codificado nos rituais coletivos. (2003, p. 30). Por isso, o mascarado nas festas encontra-se na liminaridade, entre o público que assiste e a encenação do drama, ritualisticamente representado. No caso europeu, segundo Pereira (1973), os rituais com máscaras, ou mascaradas, estão tradicionalmente ligados aos ciclos das mudanças de estação do ano. Elas acontecem durante o Inverno e o início da Primavera, associadas ao ciclo dos 12 dias, que correspondem ao período entre o Natal e a Epifania, e estendemse até o Carnaval (Entrudo).

Iniciando pela região da Galícia, zona fronteiriça entre o território português e a Espanha (La Raya ou a Raia), as mascaradas ibéricas penetram o norte de Portugal e se espalham pela região de Trás-os-Montes e Alto Douro, onde encontram solo fértil no Nordeste transmontano. Pereira reconhece na máscara europeia uma reminiscência das expressões arcaicas daquele continente, cuja principal finalidade se definia por três funções VOL.16|N.1| JUN. 2019 
específicas fundamentais: propiciatórias, apotropaicas e profiláticas: "Por vezes elas integram-se em cerimoniais que assumem caráter de verdadeiras representações dramáticas e, através de trajes e atributos, prefiguram seres sobrenaturais." (1973, p. 11).

Os três motivos apontados por Pereira podem ser igualmente percebidos, nas mascaradas dos outros continentes. Os exemplos representativos do caráter propiciatório da máscara é o primeiro meio pelo qual ela se associa aos rituais sagrados e prefigura como instrumento de mediação entre o mundo natural e o mundo subjetivo das divindades. Ela serve como mediadora de modo a propiciar o condicionamento para que o pajé, o xamã ou o sacerdote esteja apto a cerimoniar um sacrifício, ou comunicar-se com o mundo etéreo que seus olhos descobertos não podem contemplar: "Simbolicamente e dentro do espírito da religiosidade popular ou paganismo funcional, as dádivas contêm um acto propiciatório: dar para que a divindade retribua a oferta no novo ciclo da natureza, em muito maior prodigalidade" (TIZA, 2013, p. 62).

A função apotropaicas é ainda visível nos momentos em que a representação de entes maléficos como demônios e outros seres mitológicos são utilizados para expurgar os medos, tornando risível os maiores temores humanos. Uma das máscaras mais recorrente em todos os tempos é a representação zoomorfa do Diabo, que acompanha o tempo mítico, renovando as esperanças humanas de vitória do bem contra o mal. Na imagem consagrada pelo imaginário universal, Lima reconhece a primeira concepção ideológica de uma deformação caricaturada: “[...] O Diabo foi, pois, a primeira caricatura. Tem ela assim a idade do tempo. Veio dum desfôrço, e, portanto, haveria de acompanhar para todo o sempre o homem insatisfeito e oprimido [...]" $(1963,33)$.

O enunciado do Diabo como protagonista da mascarada e sua referência como à encarnação do mal é associada à figura do Careto, que aparece nas Festas de Inverno do Nordeste transmontano como um ente "diabólico", personificação das mazelas humanas, mas, por isso mesmo, aquele a quem tudo é permitido. Assim como a figura do Diabo, o mascarado chocalheiro, que figura em diversas festas transmontanas é descrito como uma entidade assustadora, cuja máscara, associada também ao barulho produzido pelo chocalho, é capaz de despertar o mais sombrio dos temores, provocando uma espécie de purgação ante a experiência do contato com sua presença, cuja função é rir-se de sua própria condição humana, limitada pelo tempo, orgulhosa de seu livre arbítrio, mas sempre irreverente, forma propiciatória, profilática, atropopaica, ou, poder-se-ia dizer, catártica. Ao descrever o chocalheiro de Bemposta, aldeia do Conselho de Mogadouro (PT), assim se refere Pereira:

\footnotetext{
Do complexo geral de mascarados portugueses, estes "chocalheiros" apresentam-se, aos olhos das gentes de raras aldeias em que sobrevivem, como uma verdadeira entidade mágica, sombria e inquietante, temida, mas necessária. A própria máscara encerra um conteúdo simbólico que não se apaga após a atuação dos mascarados: pertença da coletividade, ela é objeto de cuidados especiais. (1973, p.102)
}

Nas sociedades agrárias, a máscara está para as culturas como jubilo e renovação do mundo, ligada às festas cíclicas e associando-se às celebrações coletivas que rejuvenescem os grupos sociais pelo festejar de dias melhores, representados pelo fim das colheitas e pelas chegadas das estações. Nas aldeias transmontanas, a manutenção destes ritos festivos em datas de celebrações assinaladas no calendário cristão, tais como Natal, Epifania e Festa de Santo Estevão em 26 de dezembro, constituem-se em um longo processo de adaptação dos antigos rituais pagãos para práticas cristãs, aceitas e difundidas por todo território europeu. Deste modo, rituais 
REVISTA DO PROGRAMA DE PÓS-GRADUACÃO EM COMUNICAÇ̃̃O, LINGUAGENS E CULTURA DA UNIVERSIDADE DA AMAZÔNIA

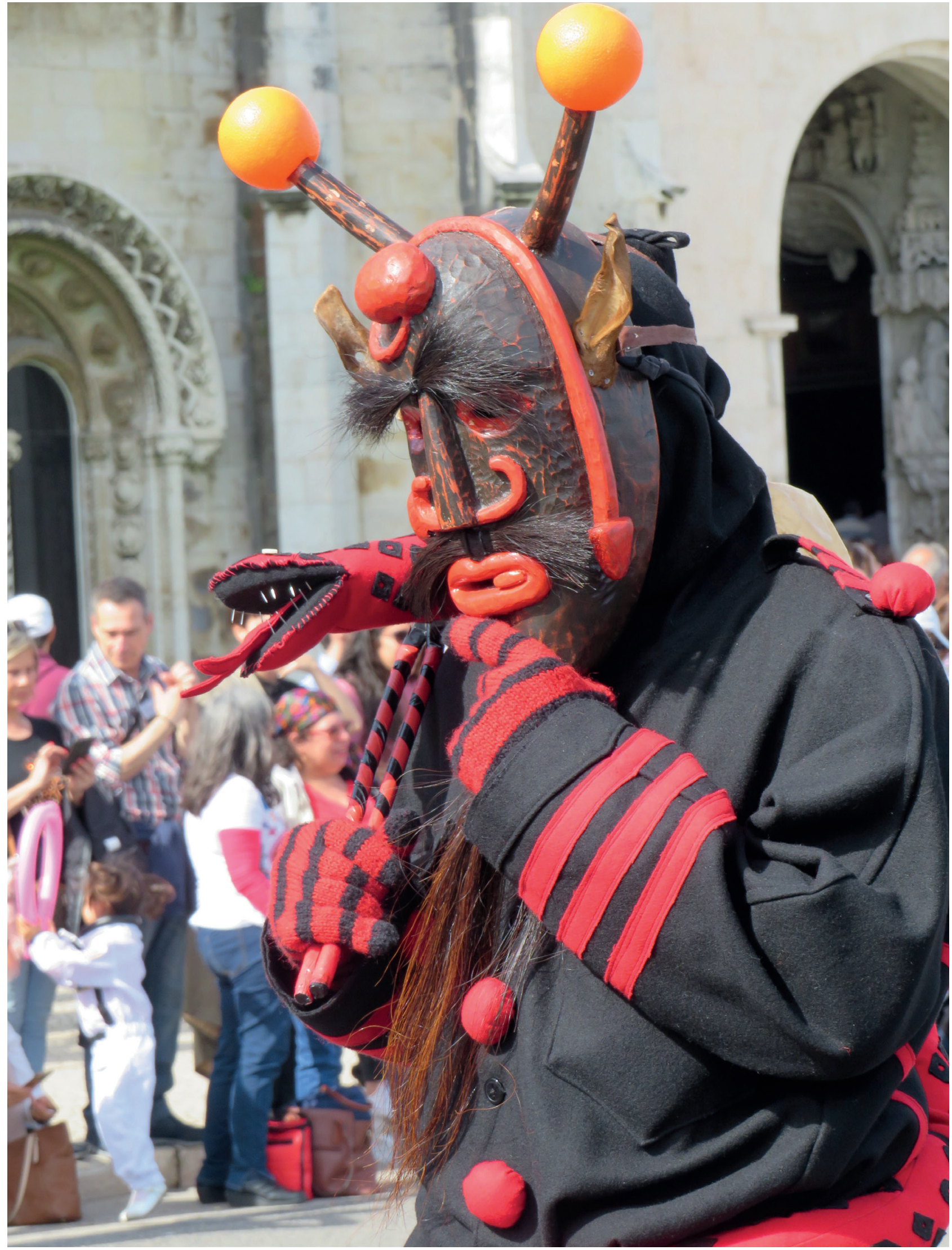

Figura 2: O Chocalheiro de Bemposta - XIV Festival da Máscara Ibérica, Lisboa, 2019. Fotografia; Silvia Silva. 
iniciáticos como a Festa dos rapazes, celebradas em diversas localidades entre os dias 25 e 26 de dezembro, passaram a ser integrados como festas comunitárias, num processo semelhante ao que se deu com o Carnaval, incluído como parte do calendário cristão e seguido pela Quaresma, que anuncia a aproximação da Páscoa, comemorada quarenta dias depois.

O caráter sagrado da máscara evanesce na transposição dos rituais agrários para as festas de rua, nas quais a coletividade apropria-se do sentido de sua representação para atribuir-lhe ainda certo aspecto sagrado, pois o mascarado permanece incógnito na multidão festiva e, mesmo ali, o uso da máscara ata-se ao mistério do oculto. Pereira (1973) lembra que tanto as cerimônias em que máscara e portador guardam a comunicação entre matéria e espírito; quanto às festas tradicionais, em que ela aparece como mera expressão lúdica, podem ser encontradas nos cinco continentes. A descrição ilustra o sentido identitário das mascaradas como representação simbólica de uma comunidade. Por outro lado, referem-se a novas concepções que surgem no seio da própria cultura, que interpela seus fazeres tradicionais em torno da construção de novos saberes compartilhados, delas, pode-se apreender que há um diálogo constante que implica na aceitação das novas gerações, com experiências sensoriais distintas daquelas de outrora, porém, com o propósito de se encontrar com sua ancestralidade e nela restaurar os elos com seu passado longínquo, como o encontro entre avós e netos para uma reunião familiar.

\section{MÁSCARAS QUE CONDUZEM TODA GENTE}

Diferindo em seu motivo e em seu formato visual e cênico, as mascaradas luso-brasileiras de São Caetano de Odivelas e do Nordeste transmontano coincidem no que se refere a sua periodização cíclica e ao poder agregador e identitário que representam para as culturas onde se originaram.

As datas do acontecimento das mascaradas nas ruas são datas ligadas às festividades cristãs, tanto no Brasil, quanto em Portugal. Entretanto, como momentos de passagem do tempo cíclico, o poder agregador da mascarada de rua constitui-se nas Festas de Inverno transmontanas e nas festas juninas de São Caetano de Odivelas, como novo e profilático motivo da máscara, que agrega grupos de jovens, famílias locais, e visitantes vindos de toda parte. Há ainda aqueles que se dedicam inteiramente ao fazer emergir a festa, e formam associações, criam páginas nas redes sociais, reúnem-se e discutem propostas e calendários das festas na localidade. Este fazer, desconectado por vezes de políticas públicas, é iniciativa de lideranças comunitárias, que seja por intuir nas mascaradas um valor identitário, seja por razões econômicas e sociais, ou apenas pelo prazer proporcionado pela festa, percebem que há um desejo pela sua continuidade, manifestado pelo apoio da maioria da população, independente de teorias e opiniões externas.

\section{A mascarada do boi de quatro pernas.}

O Boi de máscaras é uma brincadeira de rua, festa tradicional da cidade de São Caetano de Odivelas, interior do estado do Pará, que há cerca de noventa anos acontece no mês de junho, acompanhando as festas juninas, muito populares na região Norte e Nordeste do Brasil. Na tradição odivelense, há um cortejo cênico e musical que sai às ruas, ao qual se juntam os brincantes ao longo do percurso. No centro, a figura do boi que dança, elemento introduzido no Brasil a partir das brincadeiras de boi da Península Ibérica, conforme indicam os estudos de Salles (1994) e Menezes (1972). Esse boi, entretanto, difere-se das demais brincadeiras de boi de outras regiões do Brasil por apresentar a representação do boi por dois brincantes ao mesmo VOL. 16 | N.1 | JUN.2019 tempo (os pernas), enquanto os bois bumbás são representados por um único 
brincante (o tripa). Por essa representação, ele é chamado também de "boi de quatro pernas", e seu cortejo de mascarados é formado por três tipos principais: os Mascarados ou Pirrôs (Pierrôs/Pierrot), os Cabeçudos e os Buchudos.

Os brincantes odivelenses relacionam-se com seus personagens a partir da vivência da brincadeira de rua, experimentando as técnicas corporais necessárias para o uso da máscara desde a infância. As máscaras do Pirrô e do Buchudo são máscaras faciais, as indumentárias e os trajes encobrem o corpo por completo, tal e qual os fatos dos Caretos transmontanos. Já a máscara do Cabeçudo, cobre o corpo até a cintura, sendo, portanto, uma máscara corporal que limita os movimentos do portador e cria com ele um segundo corpo, o corpo do boneco Cabeçudo. O boi, vestido por dois corpos, é a maior das máscaras corporais do Boi de Odivelas. Essa última exige certa destreza da dupla de brincantes, que se movimenta simultaneamente para representar o boi que dança em suas performances.

O cortejo do boi de máscaras segue um ritual que começa em junho, mês tradicionalmente reconhecido como o tempo do boi, desde a sua origem, na década de 1930. A quadra junina ou joanina é parte do calendário de festas católicas, com as festas de Santo Antônio, São João Batista, São Pedro e São Marçal (13, 24, 29 e 30 de junho, respectivamente). Os festejos dos santos da quadra incluem os arraiais e feiras, as bandeirinhas que enfeitam as ruas e as danças típicas, acompanhadas de encenações, dentre as quais na região Norte se inclui as brincadeiras de boi. No Pará, a brincadeira do boi está ligada ao ciclo junino, diferindo de alguns estados nordestinos, nos quais ela faz parte do ciclo natalino.

Misturam-se, no cortejo do boi, personagens mascarados, músicos da orquestra que faz o boi dançar, comandando os demais mascarados, mutucas (pessoas que apreciam e acompanham o cortejo) e os organizadores da brincadeira. Todos, cada um em seu fazer, ocupam o espaço da rua: "A rua é um grande palco itinerante com cenários que se modificam a cada esquina e permite ao espectador um sem números de ângulos, que dependendo de sua escolha pode revelar aspectos diversos da mesma encenação" (SILVA, 2011, p. 69). Aqueles que saem de suas casas ao encontro do cortejo já em movimento, seguem o som da música, o movimento de ir e vir dos brincantes, integrando-se ao cenário da rua, e perguntam aos transeuntes que encontram pelo caminho: Onde está o boi? O boi está por toda cidade, formando-se pequenos quadros com cada grupo envolvido em seu fazer lúdico, como no painel de Brueghel.

\section{As mascaradas de Inverno transmontanas}

A região de Trás-os-Montes e Alto Douro situa-se no Norte de Portugal, constitui-se majoritariamente pelos distritos de Bragança e Vila Real. Nestes sítios em que o inverno é o mais rigoroso do país, acontecem os rituais com máscaras, possivelmente herança dos cultos celtas, dos povos "Zoelas", que habitaram aquela região, mais especificamente no Nordeste transmontano, na zona conhecida como "Terras Frias". Por ocasião das mudanças de estação, marcadamente entre o solstício de Inverno e equinócio de Primavera, aparecem os grupos de Caretos, personagens mascarados, cuja denominação varia de aldeia para aldeia: "Os mascarados assumem diversas designações consoante as festas, as personagens e as localidades em que atuam" (TIZA, 2013, p. 31)

Tradicionalmente na Festa dos rapazes, Festa de Santo Estevão e no Entrudo, os Caretos desempenham um papel fundamental para o sucesso da festa. Cabe a eles reunir o povo chamando atenção com suas diabruras e os sons de seus chocalhos, que em algumas celebrações anunciam a chegada dos grupos ritualísticos, que acompanham. Eles também estão presentes em 
outros momentos que fazem parte dos rituais, conforme a localidade, tais como a mesa comunitária (Festa de Santo Estevão), na qual se compartilha alimentos típicos da região, como os enchidos, os pães, as castanhas assadas. Há ainda as rondas das tabernas (Entrudo), nas quais, visitando os estabelecimentos comerciais, os Caretos bebem e comem a vontade, e as leituras do testamento do Entrudo na quarta-feira de cinzas, quando realizam a sátira social.

As mascaradas transmontanas, assim como a brincadeira de boi, também experimentaram tempos de dispersão, levando ao desaparecimento dos rituais em algumas zonas. O vazio demográfico, o êxodo dos jovens das aldeias durante a crise provocada, entre outros fatores, pela Guerra do Ultramar (1961-1974), contribuiu para a mudança de panorama, inclusive das paisagens bucólicas nas quais se davam as Festas de Inverno, anteriores a este período. A nova realidade das aldeias transmontanas levou ao quase desaparecimento das mascaradas de rua. Entretanto, novo vigor vem surgindo nas últimas décadas, fruto de uma renovação identitária daquelas culturas, que passam a ver na mascarada mais do que um retorno ao seu passado imemorável, uma possibilidade de futuro para as suas comunidades, presenciando a vinda periódica dos seus cidadãos para participar da festa, do mesmo modo como vem ocorrendo em São Caetano de Odivelas, onde por fatores diferentes, a brincadeira de boi vem ganhando nova expressão a cada ano, com o crescimento em número de participantes e de grupos em atuação. Pois, como reflete Hall: "Mas o que esse 'desvio através de seus passados' faz é nos capacitar, através da cultura, a nos produzir a nós mesmos de novo, como novos tipos de sujeitos". E, conclui-se, como se falasse do fenômeno das mascaradas de rua: "Portanto, não é uma questão do que as tradições fazem de nós, mas daquilo que nós fazemos das nossas tradições". (2003, p. 44).

\section{MASCARADAS COMO PATRIMÔNIO IMATERIAL}

Pensando em meios para cuidar ou preservar as tradições culturais de distintos povos criou-se diversas estratégias ao longo do percurso que vai desde sua descoberta como "saber popular" até as recentes questões que envolvem o tombamento de um bem como patrimônio. Deixando de lado discursos preservacionistas, que envolvem as práticas culturais em argumentos subjetivos como a "folclorização", a "identidade" e a "autenticidade", já tantas vezes discutidos, a reflexão deste tema em relação às mascaradas de rua passa pela dicotomia que divide opiniões de especialistas, antropólogos, políticos e a população diretamente envolvida nas Festas.

Ao considerar a questão da patrimonialização mundial de bens materiais e imateriais, Canclini contesta o "para quem" estes bens são de fato importantes, lembrando que o acesso a eles não é unanimidade nem mesmo nas sociedades que os produzem: "Os bens reunidos na história por cada sociedade não pertencem realmente a todos, embora formalmente pareçam ser de e estar disponíveis para todos" (2016, p. 72, grifos do autor). Esta observação pode ser aplicada as mascaradas de rua quando se percebe que, embora reconhecidas no discurso oficial como patrimônio local, elas, muitas vezes, não refletem senão o resultado do esforço dos grupos envolvidos. Entretanto, possuem em comum a possibilidade de reunir fazeres de gerações e setores distintos. A UNESCO define certas condições como critérios para reconhecer determinado bem como patrimônio imaterial da humanidade. A saber:

VOL. 16 | N.1 | JUN. 2019
R.1 O elemento é considerado patrimônio cultural imaterial, de acordo com o Artigo 2. ${ }^{\circ}$ da Convenção.

R.2. A inscrição do elemento contribuirá para assegurar a visibilidade, a tomada de consciência sobre a importância do patrimônio cultural imaterial e para favorecer $O$ diálogo, refletindo assim a diversidade cultural do mundo e testemunhando a criatividade humana.

R.3. São desenvolvidas medidas de salvaguarda que permitam proteger ISSN 1415-7950 


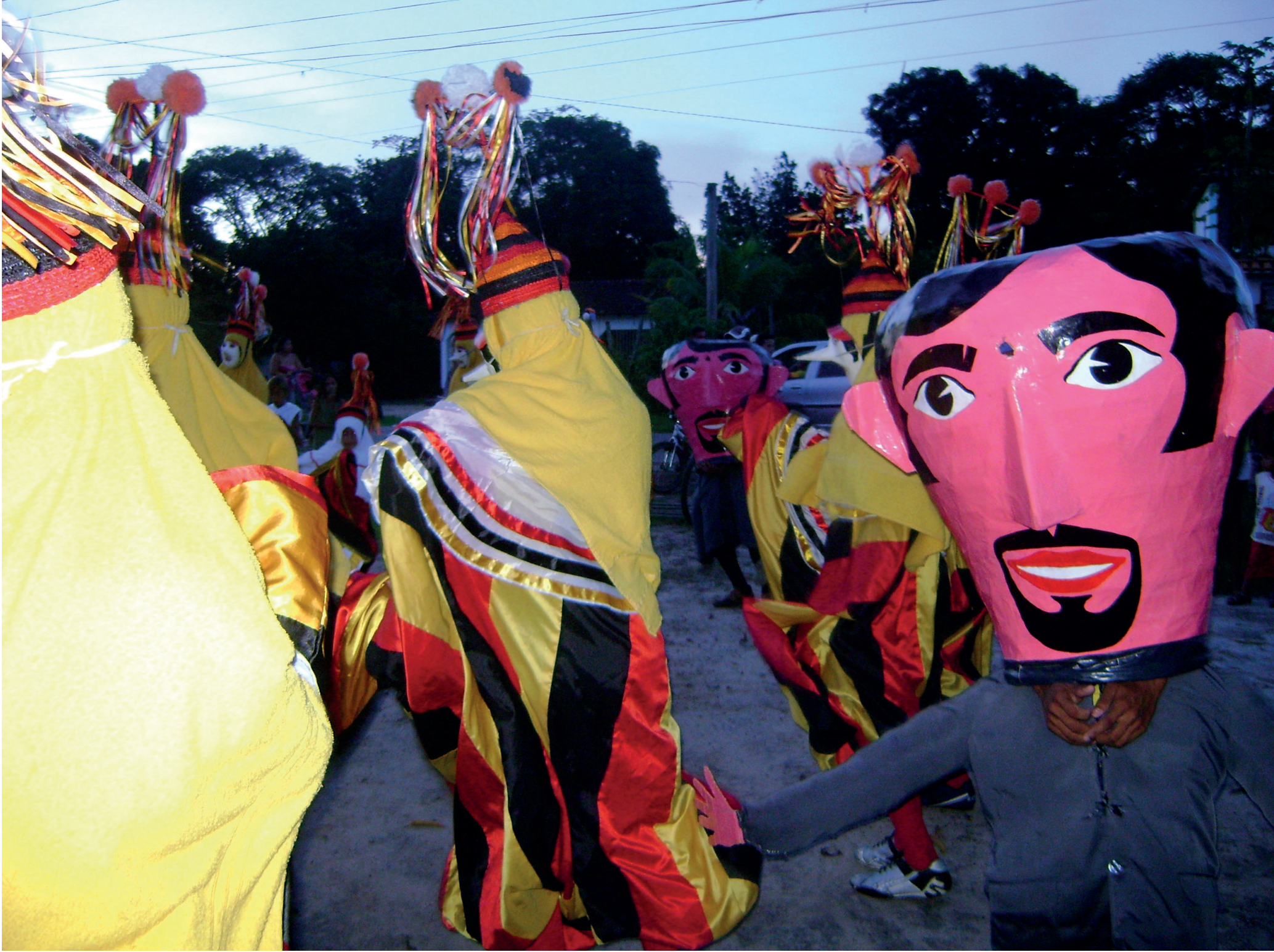

Figura 3: Brincadeira do Boi de máscaras - São Caetano de Odivelas (PA) Fotografia: Silvia Silva, 2009. 


\begin{abstract}
e promover o elemento.
R.4. O elemento foi submetido com a participação, o mais ampla possível, da comunidade, do grupo ou, sendo o caso, dos individuos em causa e com o seu consentimento livre, prévio e estabelecido.

R.5. O elemento figura num inventário de patrimônio cultural e imaterial existente no(s) território(s) do Estado(s). Parte submissionário(s), conforme os Artigos $11 .^{\circ}$ e $12 .^{\circ}$ da Convenção.
\end{abstract}

Os critérios, que independem da importância dada ao bem pela comunidade, responsabilizam em primeiro lugar todos os segmentos sociais pelo seu reconhecimento como patrimônio imaterial, declarando a necessidade de diálogos que considerem a fala dos indivíduos com a mesma valoração daqueles que teorizam sobre a cultura e a conservação de seus bens materiais. Godinho lembra que "os territórios de património remetem para uma edificação em torno da memória, ao mesmo tempo que patenteiam os terrenos de uma economia cultural, que inseriu num mercado um conjunto de bens que haviam ficado arredados do consumo" (2010, p. 107).

Apesar da aparente democracia sugerida pelas Diretrizes da UNESCO, Canclini adverte:

\begin{abstract}
[...] Contudo, no início do século XXI, tanto a lista patrimonial da UNESCO como as agendas de museus e bienais evidenciaram que, na geopolitica da cultura, as classes populares e as sociedades periféricas têm menor possibilidade de realizar operações indispensáveis para transformar seus bens em patrimônio mundializado: a) acumulá-los ao longo do tempo, sobretudo diante da pobreza ou da repressão; b) transformá-los em um saber objetivado, que não dependa de individuos ou da simples transmissão oral; c) expandi-los através da educação institucional e do aperfeiçoamento das práticas de grupos periféricos por meio de pesquisa e experimentação sistemática. (2016, p. 73)
\end{abstract}

$\mathrm{Na}$ linha de discurso antropológico, Godinho enfatiza três aspectos que devem ser levados em conta ao se falar de mascaradas contemporâneas: "Em primeiro lugar, as festas devem ser encaradas com intrínsecas a uma realidade, e não como meras representações ou formas de 'cultura expressiva', submergidas naquilo que a UNESCO denominou 'patrimônio imaterial'." (2010, p.12 - pdf) Neste primeiro ponto, exclui-se da linha da patrimonialização os eventos extracalendário que se realizam fora do espaço da Festa, ou seja, a Festa é vista de perto, no momento aurático (BENJAMIN, 1994) em que acontece sua aparição única, no contexto da rua. Assim, coadunando com Godinho, não se pode deixar de perceber a importância do tempo para o entendimento de uma festa, tempo cronológico, historicamente marcado por fatos e transformações operadas a partir destes fatos, com toda carga de alteração dos ritos tradicionais, "em que os acontecimentos externos se traduzem quer em mutações na sua sequência, quer em apropriações e re-significações diversificadas". Por fim, ela considera que toda e qualquer reflexão sobre o patrimônio de uma comunidade deve estar centrada nos "indivíduos como agentes sociais, percorrendo os papéis dos grupos, das mediações e dos conflitos através de conjunturas determinadas" (2010, p. 12 - pdf).

Soberana em sua expressão simbólica e humana, a mascarada só existe em função da cultura que a produz. Dito isso, é importante ressaltar o destino e o significado que essa lhe quer atribuir, antes de qualquer movimento em torno de sua patriomonialização. Para tal, é bastante feliz o texto da UNESCO, anteriormente citado, quando afirma a necessidade de demonstrar que o objeto do tombamento "foi submetido com a participação, o mais ampla possível, da comunidade, do grupo ou, sendo o caso, dos indivíduos em causa e com o seu consentimento livre, prévio e estabelecido". O patrimonio material ou imaterial, deve ser tombado para as gerações 
REVISTA DO PROGRAMA DE PÓS-GRADUAÇÃO EM COMUNICAC̨ÃO, LINGUAGENS E CULTURA DA UNIVERSIDADE DA AMAZÔNIA

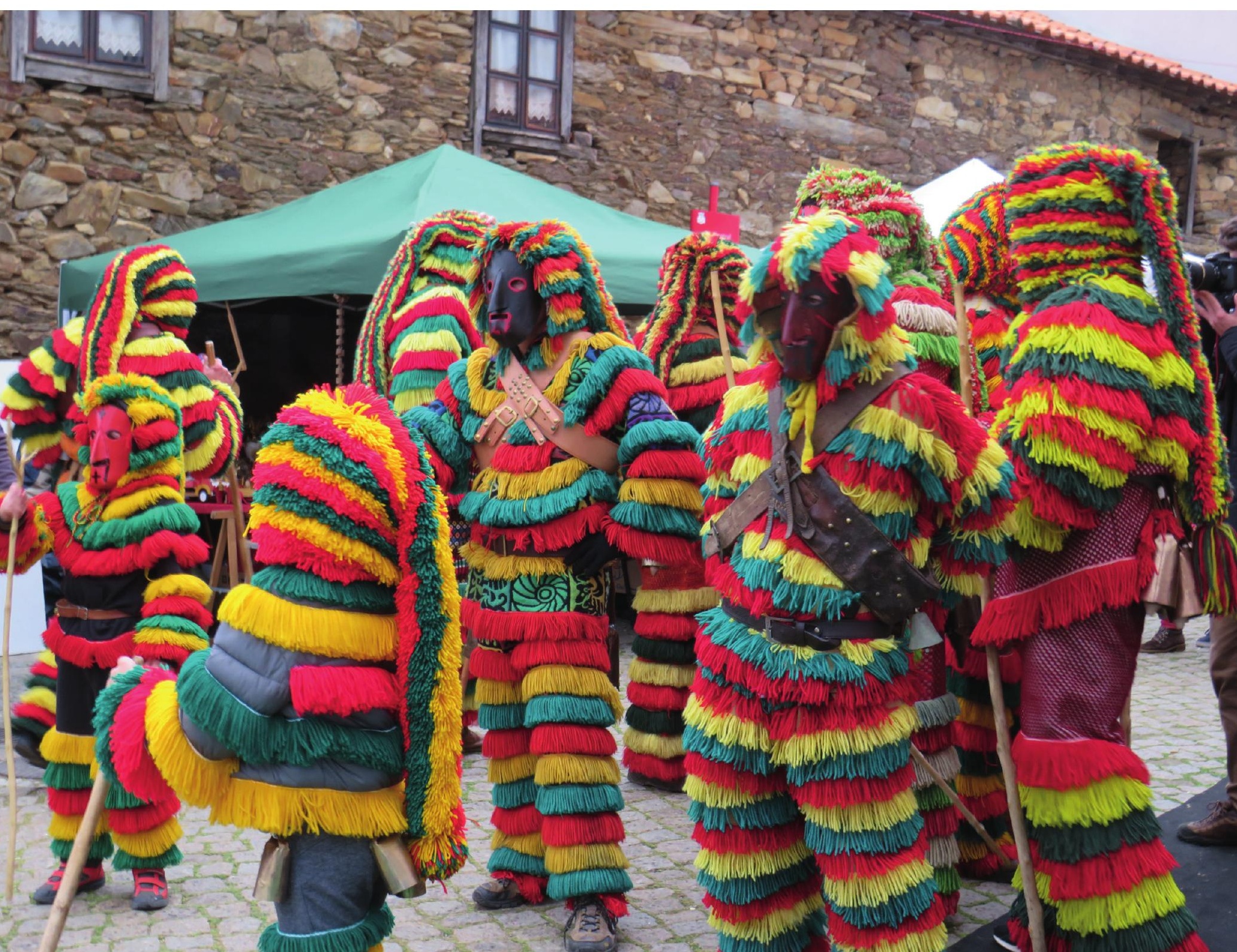

Figura 4: Caretos de Podence, entrudo chocalheiro, 2019 Fotografia: Silvia Silva 
presentes e futuras, patrimonializar não pode ser traduzido por congelar no tempo, não há que ser como certos filmes de ficção em que o protagonista fica numa capísula congelada, tal qual o Capitão América, para retornar em centenas de anos mais tarde e, só então, "salvar o mundo"!

\section{CONSIDERAÇÕES FINAIS}

O objetivo deste ensaio foi proporcionar uma reflexão sobre os novos significados e apropriações dos antigos rituais com máscaras, presentes em todos os continentes e que hoje desafiam o olhar contemporâneo, perplexo diante de um fazer comunitário e subjetivado em contraste com o mundo globalizado e individualista. Esses rituais, no que pese todas as suas alterações, aceleradas ao longo das últimas décadas, fazem a ligação entre tradições ancestrais e as novas gerações, que deles participam e imprimem sua nova marca, carregada de novas simbologias que se remetem a saberes contemporâneos, nos quais se reconhecem como sujeitos híbridos e integrados a sua cultura.

As mascaradas, como festas comunitárias, sejam elas ritos do solstício de inverno de Trás-os- Montes ou brincadeiras juninas de São Caetano de Odivelas, são bens culturais que reprezentam a expressão simbólica e criativa de uma comunidade. Às funções ritualísticas da máscara, engolidas em grande parte pela sociedade de consumo, juntam-se novas funções, que embora distanciadas de seu sentido sagrado, atribuem-lhe nova sacralidade, a medida que concedem ao seu portador a função de representar a cultura local e projetala para fora do espaço físico da rua para um espaço virtual, globalizado e ora indiferente, ora curioso sobre o que se passa em seu interior.

$\mathrm{O}$ olhar atento da comunidade externa dá as culturas um poder que sempre foi seu: o de decidir-se por empoderar-se de seu ritual, nega-lo, pulveriza-lo em novas representações distorcidas ou, usá-lo como forma de reconhecimento ou pertencimento a um lugar específico, onde a mascarada existe no imaginário fora de seu tempo e materializa-se novamente a cada novo ciclo, no momento do seu tempo ritual.

\section{REFERÊNCIAS}

ARIÈS, Philippe. História social da criança e da família. Rio de Janeiro: Guanabara, 1981.

BENJAMIN, Walter. Magia e técnica, arte e política: ensaios sobre literatura e história da cultura. São Paulo: Brasiliense, 1994.

BIÃO, Armindo Jorge de Carvalho. Etnocenologia e a cena baiana textos reunidos. Salvador: P\&A, 2009.

CANCLINI, Néstor. $A$ sociedade sem relato: Antropologia e Estética da Iminência. São Paulo: Edusp, 2016.

CERTEAU, Michel de. A Invenção do Cotidiano. 1. Artes de Fazer. Petrópolis: Vozes, 1996.

DEBORD, Guy. A Sociedade do espetáculo. eBooksBrasil.com - Fonte Digital base Digitalização da edição em pdf originária de www.geocities.com/projetoperiferia. http://www.ebooksbrasil.com/eLibris/socespetaculo.html, 2003.

DUVIGNAUD, Jean. Festas e civilizações. Rio de Janeiro: Tempo Brasileiro, 1993.

GODINHO, Paula. Festas de inverno no nordeste de Portugal património, mercantilização e aporias da "cultura popular". Castro Verde: 100 Luz, 2010.

VOL. 16 | N.1 | JUN.2019 HALL, Stuart. Pensando a diáspora reflexões sobre a terra no exterior. In: HALL, ISSN 1415-7950 Stuart. Da diáspora: Identidades e mediações culturais. Org. Sovik; Belo Horizonte: 
Editora UFMG; Brasília: Representação da UNESCO no Brasil. (Humanitas), 2003.

LIMA, Herman. História da caricatura no Brasil. Rio de Janeiro: José Olímpio, 1963.

MINOIS, Georges. História do riso e do escárnio. São Paulo: Ed. UNESP, 2003.

MENEZES, Bruno de. Boi-bumbá auto popular. Belém: Imprensa Oficial, 1972.

PEREIRA, Benjamim. Máscaras portuguesas. Lisboa: Museu de Etnologia do Ultramar, 1973.

RAPOSO, Paulo. Virando o outro em Podence: máscaras da pós-ruralidade. In: AntropolíticA. n. 30 (PP. 131-149) Niterói, 2011.

SANTA BRÍGIDA, Miguel. O Maior Espetáculo da Terra: o desfile das Escolas de Samba do Rio de Janeiro como cena contemporânea na Sapucaí. Tese (Doutorado em Artes Cênicas) - Programa de Pós-Graduação em Artes Cênicas, UFBA, Salvador, 2006.

SALLES, Vicente. Épocas do Teatro no Grão-Pará ou Apresentação do Teatro de Época. Belém: Ed. Universitária UFPA, 1994.

SILVA, Silvia Sueli Santos da. O Boi e a máscara: imaginário, contemporaneidade e espetacularidade nas brincadeiras de boi de São Caetano de Odivelas - Pará. 244p. TESE (Doutorado em Artes Cênicas) - Universidade Federal da Bahia, Salvador, 2011.

TIZA, António Pinelo. Máscara e danças rituais - ritos ibéricos do solstício de inverno. Lisboa: Eranos, 2013.

UNESCO. Diretrizes Operativas para a Aplicação da Convenção para a Salvaguarda do Património Cultural Imaterial | Paris: 2018. Disponível em: https://www.unescoportugal.mne.pt/images/cultura/diretrizesoperativaspci pt_2018_4.pdf.

\section{NOTAS}

1 Observadores e estudiosos da obra de Brueghel (1525/30-1569, Breda - Países Baixos - atual Holanda) divergem quanto às pessoas representadas na cena. Pela obra intitular-se "Jogos Infantis", ou em outras traduções "Brincadeiras Infantis", acredita-se que se trata de crianças brincando. Entretanto, a semelhança com os adultos retratados por Brueghel em outras obras coloca em dúvida se aqueles não seriam também adultos participando de jogos infantis, uma vez que, como lembra Ariès (1981), esses jogos nesse período eram atividades praticadas indistintamente por adultos e crianças. Por outro lado, não havia para a criança nem mesmo um conceito quanto a sua condição humana, sendo esta vista sempre como um adulto em miniatura. "No mundo das fórmulas românticas, e até o fim do século XVIII, não existem crianças caracterizadas por uma expressão particular, e sim homens de tamanho reduzido" (ARIÈS, 1981, p. 51).

2 São Caetano de Odivelas é uma das nove cidades situadas na mesorregião Nordeste do Pará ou mesorregião do Marajó, da qual faz parte a microrregião do Salgado paraense. A sede do município está localizada a $95 \mathrm{~km}$ de Belém (capital do Pará), é banhada pelo rio Mojuim e atravessada pela rodovia PA-140. Ao Norte está o Oceano Atlântico, a Leste os municípios de Curuçá, São João da Ponta, Santo Antônio do Tauá e Terra Alta; ao Sul e a Oeste está a cidade histórica de Vigia de Nazaré.

3 Atualmente está em processo a Candidatura conjunta de Espanha e Portugal junto à UNESCO, propondo as mascaradas da Comunidade Intermunicipal Terras de Trás-osMontes, Salamanca e Zamora como patrimônio imaterial da humanidade. 
REVISTA DO PROGRAMA DE PÓS-GRADUAÇÃO EM COMUNICAÇÃO, LINGUAGENS E CULTURA DA UNIVERSIDADE DA AMAZÔNIA

Silvia Sueli Santos da SILVA

Doutora em Artes Cênicas, Universidade Federal da Bahia (UFBA), Docente do Instituto Federal de Educação, Ciência e Tecnologia do Pará (IFPA). Integrante do Grupo de Estudos em Gênero e Performance -GECE; Núcleo de Estudos em Cultura e Ócio - NECO e Grupo Interdisciplinar de Pesquisa em Arte, Cultura e Educação - GIPACE. Investigadora visitante no Centro de Línguas, Literaturas e Culturas, Programa Doutoral em Estudos Culturais da Universidade de Aveiro (PT). E-mail: silvia.sueli.silva@gmail.com. 